\title{
EDZNÁ Y LA REGION OCCIDENTAL DEL PUUC
}

\author{
Antonio Benavides C. \\ Centro INAH Campeche
}

El patrimonio precolombino de la porción occidental de la península yucateca ha sido objeto de diversos estudios e investigaciones desde mediados del siglo xIx. Desde el principio los elementos más llamativos han sido los edificios recubiertos con sillares bien cortados, hoy generalmente conocidos como Puuc, y que, en medio de una densa vegetación, han perdurado a través de un promedio de 12 a 14 siglos. En buena medida su conservación se debe a su calidad constructiva. Por desgracia, el deterioro sufrido por los inmuebles mayas ha sido ocasionado por el crecimiento de muchas generaciones de árboles y vegetales diversos, por la exposición a factores ambientales y, tristemente, por las operaciones ocasionales de saqueadores y vándalos.

Los primeros reportes de construcciones con arquitectura en pie caracterizada por el uso de bloques muy bien labrados y ensamblados datan de 1842, año en el que John L. Stephens y Frederick Catherwood iniciaron la difusión internacional de la riqueza arqueológica de esa región del sureste de México. Después, a fines del siglo xIx otros exploradores incursionaron por los poblados y parajes selváticos peninsứlares, especialmente Teoberto Maler $(1895,1902,1997)$, quien realizó intensos recorridos y registros sistemáticos en el sur de Yucatán, en el norte y en el centro de Campeche. Esta labor incrementó notablemente el número de sitios mayas entonces conocidos.

A lo largo del siglo $\mathrm{xx}$ varias instituciones y muchos investigadores prosiguieron la tarea de visitar y documentar esa región hoy conocida como Puuc. El término puuc, de origen maya yucateco, hace referencia a una serie de colinas bajas que rompen la monotonía relativamente plana del septentrión peninsular y en cuyas cimas y valles intermedios encontramos los asentamientos precolombinos caracterizados por edificios recubiertos con bloques pétreos muy bien cortados y ensamblados. Lo que en principio eran datos llamativos e informaciones dispersas fue analizado e interpretado, de modo que hoy hablamos de una región en la que predomina un estilo arquitectónico general, subdividido temporalmente de acuerdo a variantes constructivas claramente definidas (Pollock 1980; Andrews 1986 y 1995).

En números redondos, en Campeche y Yucatán actualmente se conocen unos 430 asentamientos con inmuebles cuya arquitectura ha sido clasificada como perteneciente al estilo Puuc. Esta cifra aproximada procede de la revisión de sitios reportados en el Atlas Arqueológico de Yucatán (Garza y Kurjack 1980), así como de las obras de Harry Pollock (1980), Nicholas Dunning (1992), George Andrews (1995), Lorraine Williams- 
Beck (1998) y de diversos reportes inéditos o publicados en revistas especializadas por investigadores como Karl Herbert Mayer y Hanns Prem, entre otros.

Cabe comentar que todos los límites de la región del Puuc comúnmente aceptados deben revisarse con base en reportes recientes de sitios con dicha arquitectura que se localizan allende aquellas líneas imaginarias. Si bien es difícil señalar la extensión de la región, analizando los planos generales de quienes más han tratado el tema de manera global, encontramos las cifras aproximadas siguientes: Harry Pollock (1980: II) propone $9000 \mathrm{~km}^{2}$ sin especificar los límites; Paul Gendrop (1983: 150) plantea una "amiba" de unos $7000 \mathrm{~km}^{2}$ y George Andrews (1986: 8) se inclina por un área triangular que cubre un promedio de $5500 \mathrm{~km}^{2}$.

Es curioso observar que las extensiones decrecieron conforme pasaron los años. También debemos recordar que Pollock publicó casi 40 años después de haber realizado su trabajo de campo y que durante esas cuatro décadas se descubrieron más sitios. Por lo visto, el fenómeno Puuc no fue apreciado, desde el punto de vista de extensión geográfica, con suficiente profundidad por los investigadores recientes. En consecuencia, era muy posible que los $9000 \mathrm{~km}^{2}$ de Pollock fueran una superficie inicial destinada a incrementarse y ello se confirma con los recorridos y registros efectuados en los últimos años.

El criterio fundamental para hablar de una provincia estilística o de una región arqueológica Puuc ha sido la presencia de inmuebles con dicha impronta. En este sentido, las evidencias arqueológicas actuales nos indican que existen edificios con arquitectura Puuc en sitios del centro de Campeche como Xkanacol, Ley Federal de Reforma Agraria y Yohaltún; así como en asentamientos de la costa o cerca de ella: Sihó, Xcacab, Xuelén, Boxol, Uayamón, Seybaplaya, Villa Madero y Ulumal, entre otros. Por otro lado, no debemos olvidar los inmuebles Puuc existentes en sitios del norte y occidente de Yucatán como Dzibilchaltún, Acanceh y Mayapán, o bien aquellos otros del oriente yucateco: Chichén Itzá, Yaxuná, Arco Opchén (a unos $26 \mathrm{~km}$ al oriente de Buctzotz) y, francamente en el lado este de dicha entidad: Ekbalam y Culubá.

En cuanto a Jaina, en las temporadas de 1997 y 1998 observamos dos variantes constructivas de la arquitectura monumental. La primera presenta bloques burdamente desbastados, que recuerdan lo Petén, y la segunda tiene sillares muy bien labrados, a la usanza Puuc. Ello concuerda con las observaciones que hiciera Miguel Angel Fernández (1946) hace más de medio siglo y que no parecen haber sido escuchadas por quienes laboraron después en la ínsula.

Entre el límite sur de la región Puuc tradicional (sur de Yucatán y norte de Campeche) y los sitios del centro de Campeche hay más de $100 \mathrm{~km}$ de distancia. Además, en diversos puntos intermedios hay buen número de lugares que también lucen la arquitectura Puuc. Aquí podemos citar, entre otros, a Carlos Salinas, Nayarit de Castellot, Lubná, Kayal y Tohcok. En consecuencia, un nuevo cálculo para la extensión geográfica del occidente peninsular en la que se han detectado vestigios arquitectónicos Puuc es aquel de $16000 \mathrm{~km}^{2}$. Más adelante propondremos un ejercicio para tratar de entender cómo estaban organizados algunos de esos asentamientos precolombinos, en especial aquellos del norte de Campeche. Hagamos ahora un breve paréntesis para referirnos a Edzná, sitio que también se encuentra en el occidente de la península yucateca e inmerso en ese gran espacio denominado región del Puuc. 
La ciudad maya de Edzná fue reportada en 1906 pero comenzó a explorarse en 1928. Las primeras excavaciones tuvieron lugar en los sesenta, y especialistas como Pollock (1980), Gendrop (1983) y Andrews (1984) en la década de 1980 insistieron en señalar a Edzná como poseedora de un estilo regional propio contemporáneo a lo Puuc, a lo Chenes y a lo Río Bec, si bien reconocieron elementos Chenes y Puuc en los inmuebles de Edzná.

La idea de Edzná como foco de una región estilística implica la existencia de varios otros sitios similares, por ejemplo una veintena, como la reportada hasta ahora para la región de Río Bec (Ruppert y Denison 1943; Bueno 1999). Sin embargo, hemos observado que los asentamientos circunvecinos de Edzná presentan características tanto Puuc como Chenes. Algunos ejemplos son Lubná y Pich (Puuc) y Xcacabcutz (Chenes).

Por otra parte, en la región de los Chenes tenemos varios sitios "híbridos", "transicionales" o como quiera llamárseles, vinculando elementos Puuc y Chenes en una sola construcción o bien por separado. Algunos ejemplos campechanos son Santa Rosa Xtampak, Macobá y Tohcok. Otro caso similar es Xkichmook, ya en terreno yucateco. Más al norte, en lo que se ha dado por llamar el corazón del Puuc, también encontramos lugares en donde se mezclan características arquitectónicas diferentes, recuérdense Uxmal (con varias subestructuras en el basamento piramidal de El Adivino y una subestructura Chenes en la esquina noroeste de la Plataforma del Gobernador); Oxkintok (con obras peteneras como el Satunsat y muy bellos ejemplos de franca arquitectura Puuc en otros inmuebles como los palacios Chich y del Diablo o CA-7 y CA-8) (Valiente, 1989) y Yaxhom, en donde una red de calzadas conecta buenos ejemplos de obras Puuc en los varios grupos llamados Cooperativa con aquel de bloques monolíticos llamado Nucuchtunich (Dunning, 1992).

Lo anterior nos lleva a replantear la idea de las regiones con base en estilos arquitectónicos, pues por lo visto hubo una fuerte interacción entre los muchos asentamientos mayas y las varias zonas o regiones en las que los hemos agrupado. A ello hay que agregar las superposiciones derivadas de construcciones erigidas conforme transcurrieron los años.

El uso de regiones estilísticas siempre tendrá que hacer frente al difícil problema de la clara definición de sus límites, asunto que quizá no sea tan interesante como el problema de las interacciones regionales, el de la cronología o el de la dinámica interna de cada región.

A nuestro juicio Edzná no pertenece a ninguna región estilística en particular, sino que conformó su propia región de dominio político y económico en diferentes momentos de su historia. Esto significa que la manera de construir y de decorar los edificios fue menos importante que la relación de un asentamiento grande para con los sitios menores circundantes.

Las dimensiones de los inmuebles y la extensión del sitio indican una concentración de bienes y de servicios que no se dio al azar sino por mecanismos de poder. Esos mecanismos de poder o fuerza política se expresaron a través de la arquitectura, de la escultura, de la pintura mural, etcétera. Es decir a través del arte e iconografía oficiales; a través de las obras públicas y/o privadas monumentales vinculadas a las autoridades de alto rango. 
Edzná fue una capital regional entre los años 300 y 1000 de nuestra era y en la antigua ciudad existen edificios con estilos arquitectónicos Petén, Chenes, Puuc (posiblemente chontales) y Tardíos que nos hablan de su desarrollo a través del tiempo. Además de inmuebles, existen tiestos, monumentos esculpidos y piezas de estuco modelado que también denotan un proceso de transformación de las sociedades precolombinas que dieron vida a Edzná.

Otro elemento monumental que comparte Edzná con algunas otras ciudades mayas desde los primeros siglos de nuestra era es un sistema de calzadas o caminos de piedra que reforzaba la cohesión del núcleo cívico-religioso, demuestra la capacidad de organización del trabajo colectivo y seguramente facilitaba y permitía controlar el desplazamiento de personas y mercancías en el ámbito zonal (Figura 1).

\section{El panorama regional}

Y ya que hablamos de un desarrollo arquitectónico en Edzná, volvamos la mirada al norte, a la llamada región occidental del Puuc. La evolución de la arquitectura Puuc nos ha sido presentada como una sucesión de fases: Oxkintok Temprana, Proto-Puuc, Puuc Temprana, Junquillo, Mosaico y Uxmal Tardía (Pollock 1980; Andrews 1986, 1995).

Para darle nombre a esa primera manera de construir se tomó como base el sitio en donde se identificó con mayor facilidad (Oxkintok). No obstante, si observamos con atención, gracias al avance de los registros arquitectónicos hoy vemos que podría llamársele Acanmul Temprano, Bakná Temprano, Kankí Temprano, etcétera por existir en esos y en otros asentamientos. Pero más interesante aún es el hecho de que esa forma primitiva de erigir construcciones de piedra no sólo ocurrió en el occidente del Puuc; hoy sabemos que se registró a lo largo y ancho de la península yucateca.

Estamos hablando de una arquitectura caracterizada por el uso de bloques pétreos regularmente cortados y luego cubiertos con un aplanado de estuco. Las techumbres fueron logradas mediante el arco falso basado en lajas saledizas. Los espacios así obtenidos en principio fueron pequeños y después aumentaron conforme mejoró la calidad de la mampostería. En el exterior fue común el uso de motivos de estuco modelado para plasmar decoración y/o mensajes iconográficos. Sobre el techo de los inmuebles más elevados se agregó un amplio remate o crestería para realzar la monumentalidad de la construcción.

Esa arquitectura primitiva es la misma que se ha llamado Petén en el norte de Guatemala, en Belice y en las regiones sureñas de Campeche y Quintana Roo (Ruppert y Denison, 1943; Hansen, 1998). Al igual que esta última, la arquitectura primitiva de la península yucateca no aparece aislada, sino acompañada de materiales cerámicos y escultóricos tempranos.

En la parte occidental de la península tuvo lugar después buena parte del desarrollo arquitectónico Puuc, el que comúnmente identificamos por el muy buen labrado de los sillares de recubrimiento. Pero, como hemos señalado, esa evolución Puuc no estuvo exenta de nuevas aportaciones, como la Chenes o la de grandes bloques (¿reminiscencias peteneras?) antes mencionadas. 

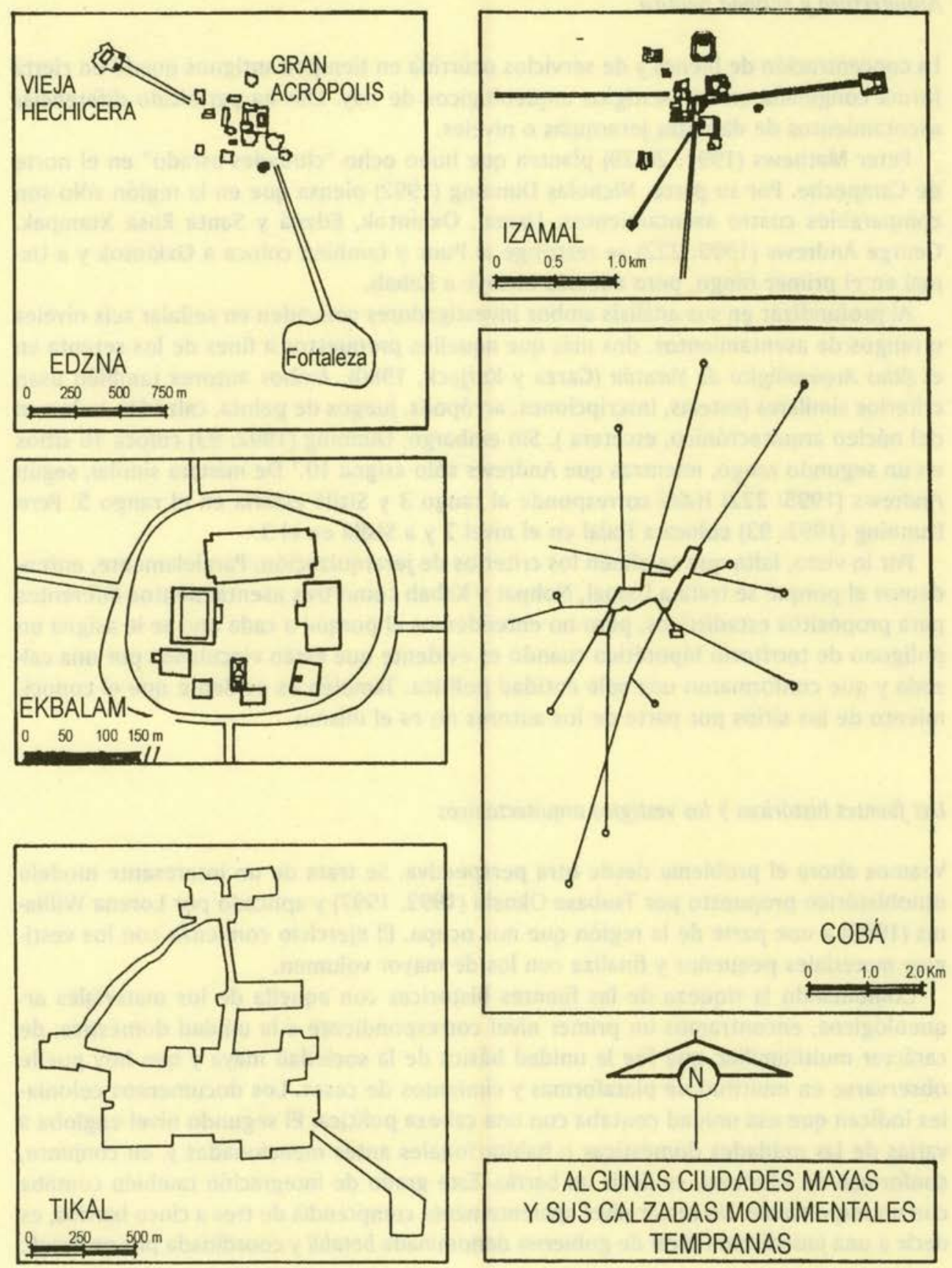

Figura 1. Algunas ciudades mayas y sus calzadas

Benavides C. / edzná y la región occidental del puUC

Estudios de Cultura Maya. Vol. XXIII, 2003

Instituto de Investigaciones Filológicas/

Centro de Estudios Mayas, UNAM

ISSN 0185-2574 
La concentración de bienes y de servicios ocurrida en tiempos antiguos quedó en cierta forma congelada en los vestigios arqueológicos de hoy. Ello ha permitido diferenciar asentamientos de distintas jerarquías o niveles.

Peter Mathews (1991: 28-29) plantea que hubo ocho "ciudades-estado" en el norte de Campeche. Por su parte, Nicholas Dunning (1992) piensa que en la región sólo son comparables cuatro asentamientos: Uxmal, Oxkintok, Edzná y Santa Rosa Xtampak. George Andrews (1995: 222) se restringe al Puuc y también coloca a Oxkintok y a Uxmal en el primer rango, pero además incluye a Kabah.

Al profundizar en sus análisis ambos investigadores coinciden en señalar seis niveles o rangos de asentamientos, dos más que aquellos propuestos a fines de los setenta en el Atlas Arqueológico de Yucatán (Garza y Kurjack, 1980). Ambos autores también usan criterios similares (estelas, inscripciones, acrópolis, juegos de pelota, calzadas, volumen del núcleo arquitectónico, etcétera ). Sin embargo, Dunning (1992: 93) coloca 16 sitios en un segundo rango, mientras que Andrews sólo asigna $10 .^{1}$ De manera similar, según Andrews (1995: 222) Halal corresponde al rango 3 y Sisilá estaría en el rango 5. Pero Dunning (1992: 93) coloca a Halal en el nivel 2 y a Sisilá en el 3.

Por lo visto, falta que se afinen los criterios de jerarquización. Paralelamente, entendemos el porqué se trata a Uxmal, Nohpat y Kabah como tres asentamientos diferentes para propósitos estadísticos, pero no entendemos el porqué a cada uno se le asigna un polígono de territorio hipotético cuando es evidente que están vinculados por una calzada y que conformaron una sola entidad política. También es evidente que el conocimiento de los sitios por parte de los autores no es el mismo.

\section{Las fuentes históricas y los vestigios arquitectónicos}

Veamos ahora el problema desde otra perspectiva. Se trata de un interesante modelo etnohistórico propuesto por Tsubasa Okoshi $(1992,1997)$ y aplicado por Lorena Williams (1998) a una parte de la región que nos ocupa. El ejercicio comienza con los vestigios materiales pequeños y finaliza con los de mayor volumen.

Combinando la riqueza de las fuentes históricas con aquella de los materiales arqueológicos, encontramos un primer nivel correspondiente a la unidad doméstica, de carácter multifamiliar, que fue la unidad básica de la sociedad maya y que hoy puede observarse en multitud de plataformas y cimientos de casas. Los documentos coloniales indican que esa unidad contaba con una cabeza política. El segundo nivel engloba a varias de las unidades domésticas o habitacionales antes mencionadas y, en conjunto, conforman un kúuchteel, es decir un barrio. Este grado de integración también contaba con un responsable. Un tercer nivel aparentemente comprendía de tres a cinco barrios, es decir a una jurisdicción local de gobierno denominada batabil y coordinada por un batab.

1 Es justo decir que coinciden en ocho ciudades: Acanmul, Itzimté, Mulucktzekel, Nohpat, Sayil, Xcorralché, Yakalxiú y Yaxhom. 
La unión de varios batabil (o batabiloob) con sus correspondientes batabes (o bataboob) conformaba un cuarto nivel de integración política que las fuentes históricas llaman kuuchkabal y que los españoles del siglo xvi reconocieron como "provincias", es decir entidades geográficas de determinada extensión con su propia organización política, con una capital o población rectora de la que dependían o a la que estaban sujetas varias poblaciones menores con sus respectivas autoridades, de la forma antes resumida.

Otro nivel de organización política superior sería el tzucub, que incluiría a los gobernantes por linajes $\sim$ familias y a otras autoridades de alto rango. Posiblemente en este nivel estarían algunos conjuntos arquitectónicos monumentales como los estudiados en Halal y Sisilá por Williams (1998). De manera similar aquí podría agregarse a Tzum, con cinco grupos arquitectónicos monumentales unidos por cuatro calzadas internas (Von Euw, 1977: 48-49).

Observamos entonces que una clave importante para el análisis de la arquitectura maya es la definición de unidades de análisis. En otras palabras, los grupos de edificios son distintos principalmente por la inversión de materiales constructivos, por la distribución y orientación de sus espacios, por la cantidad y calidad de sus elementos simbólico-decorativos.

Los propósitos e intereses de los constructores mayas están plasmados en lo que hoy perdura de sus inmuebles. Para entender y explicar ese patrimonio cultural toca al investigador precisar cuáles son las unidades de análisis que empleará: conjuntos de patios no formales, conjuntos de patios formales, conjuntos de acceso restringido, conjuntos escalonados polivalentes, etcétera. Esa tarea también implica una ardua labor de registro en campo, un serio estudio comparativo y una cuidadosa asignación de funciones a los espacios arquitectónicos, actividades que paulatinamente van realizándose.

También es muy importante recordar que el modelo teórico arriba referido tiene su origen fundamentalmente en el análisis de fuentes históricas de los siglos xv y xv. Ello debe de tomarse en cuenta al estudiar entidades políticas que existieron varios siglos antes. Es posible que algunos elementos "identificables" mediante las categorías derivadas del modelo teórico lo sean debido a su conservación a través del tiempo. Los grupos de patio, por ejemplo, son una forma de distribución espacial de los inmuebles que aparece desde el periodo Preclásico y que podemos "rastrear" hasta el Posclásico Tardío. Ello no significa que para las varias sociedades que lo presenten podamos asignar la misma estructura jerárquica u organización socio-política. Es menester ubicar dichos grupos de patio en sus respectivos contextos (con otros grupos similares, con el núcleo del asentamiento, con las características básicas de los inmuebles que integran dicho grupo de patio, etcétera), así como ponderar otros factores que permitan hablar con mayor seguridad del papel jugado (económico, político, religioso, comercial, etcétera) por los conjuntos de datos que logremos obtener del trabajo de campo. En consecuencia, el uso de términos indígenas que tienen una connotación específica para la función institucional que desempeñaron en los siglos xv y xvı debe aplicarse con cuidado. Como entidades vivas y cambiantes, es muy posible que dichas instituciones no se llamaran así durante los periodos Clásico Temprano o Tardío, o que estuviesen organizadas y funcionando de igual modo que aquellas que nos reportan las fuentes de inicios del periodo virreinal. 
Un aspecto relevante de la distribución de los asentamientos más grandes del occidente de Campeche es que se localizan a una distancia promedio de $20 \mathrm{~km}$. Esto parece obedecer, como sucede en otras regiones del área maya, a la existencia de unidades políticas diferentes. En cada una observamos una concentración de bienes y servicios hoy detectables por la extensión de los sitios, por la volumetría (cantidad y calidad de sus inmuebles) y por elementos epigráficos. Entre zonas con estas características se han registrado pequeñas localidades que quizá fungieron como satélites (o dependientes) de su vecino mayor más cercano.

Hay que tener presente que en el mundo maya actual, como en el prehispánico, recorrer una distancia de $20 \mathrm{~km}$ equivale a una jornada diaria de caminata. No hay que olvidar que también esa cifra, aproximada, es la que se ha reportado como la longitud de varias calzadas de piedra en varios puntos de la península yucateca. Algunos ejemplos son los de los sacbeoob que unen Uxmal y Kabah (18 km), Ucí y Cansahcab (también 18 km) o bien los sitios conectados por la calzada Yaxuná-Cobá; la vía Cobá-lxil (Benavides, 1981) o el camino de $21 \mathrm{~km}$ de longitud entre El Mirador y Tintal (Matheny, 1987: 336).

Si suponemos que las entidades políticas ejercían poder en un radio aproximado de $20 \mathrm{~km}$ obtenemos una superficie "controlada" de $1200 \mathrm{~km}^{2}$ en promedio. Sin embargo, al ubicar a los sitios cuyos vestigios arqueológicos indican su pretérita relevancia, elaboramos un modelo de polígonos irregulares que se ajustan a sus distancias intermedias y encontramos promedios distintos para cada entidad. Las variaciones dependen de diversos factores. Uno de ellos es su ubicación sobre la costa, característica que tiende a extender áreas en forma lineal, a lo que debió ayudar el ágil traslado mediante embarcaciones. Otra variable deriva de la relativa cercanía de un vecino poderoso. El estado actual de la investigación y del conocimiento que tenemos de los asentamientos registrados es otro factor que seguramente influye en los resultados. No obstante, en el ejercicio aquí presentado obtuvimos superficies que van desde un promedio de $870 \mathrm{~km}^{2}$ (Chunkán - Villa Madero) hasta unos 2800 km² (Edzná).

Con excepción de Edzná, estos cálculos son mucho menores que el propuesto $\left(2500 \mathrm{~km}^{2}\right)$ por Peter Mathews para las "ciudades estado" que existían alrededor del año 790 d. C. (Mathews, 1991: 28-29). Dicho autor señala la posibilidad de que hayan existido 12 de tales entidades en el norte de Campeche. Su argumentación parece basarse en una rápida revisión de los sitios más conocidos en el septentrión campechano (si bien no menciona claramente cuáles son y sólo les asigna un número sin mayor explicación) y una generalización similar aplicada a la región del Petén y a la cuenca del Usumacinta.

Desde nuestra perspectiva, para los $10000 \mathrm{~km}^{2}$ del norte de Campeche (Figura 2) los asentamientos más importantes durante el Clásico Tardío (600-900 d. C.), considerando vestigios arquitectónicos visibles y cerámica de superficie, serían los 11 siguientes: 


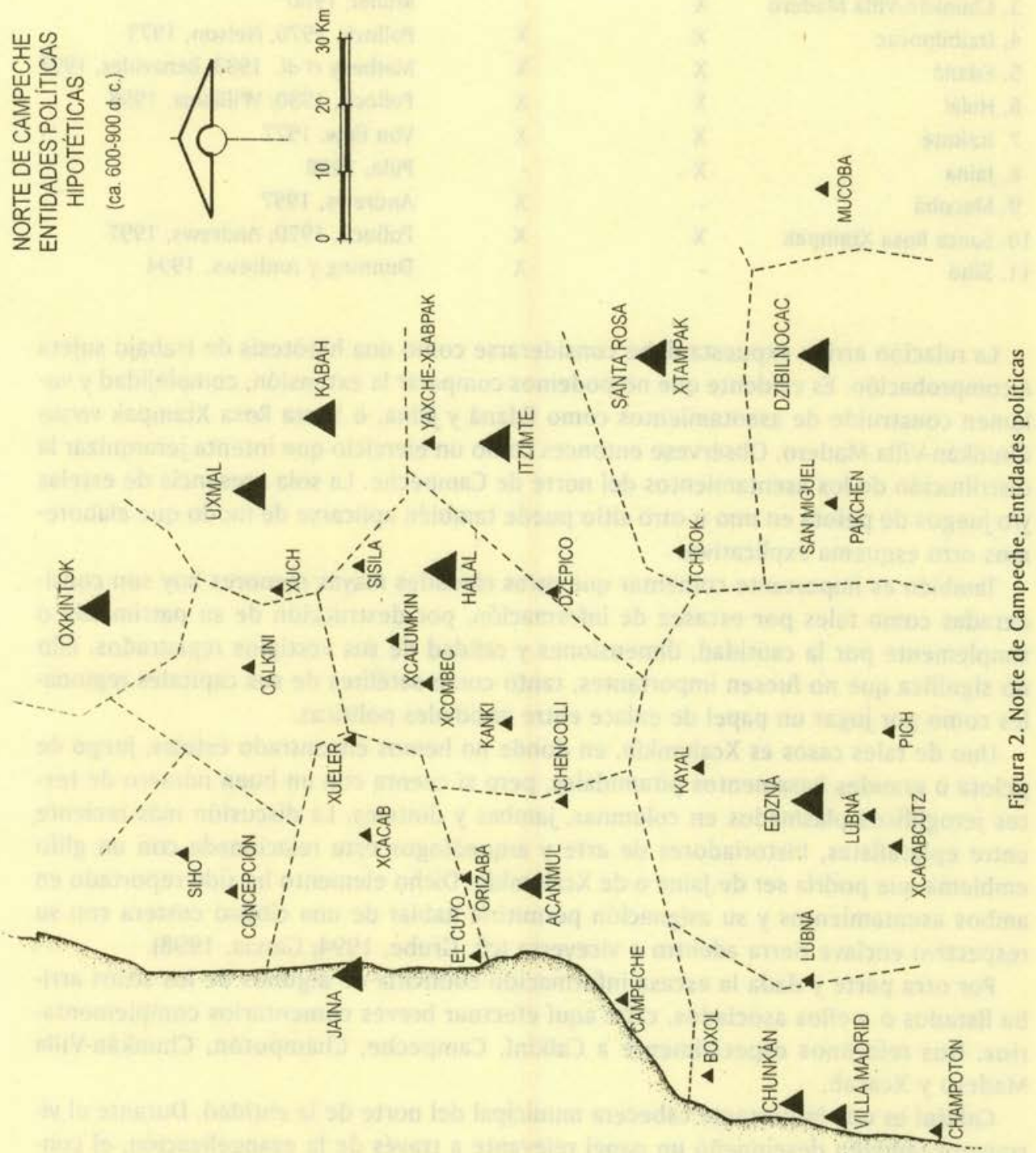

Estudios de Cultura Maya. Vol. XXIII, 2003

Instituto de Investigaciones Filológicas/

Centro de Estudios Mayas, UNAM

ISSN 0185-2574 
en pie

1. Acanmul

2. Calkiní

3. Chunkán-Villa Madero

4. Dzibilnocac

5. Edzná

6. Halal

7. Itzimté

8. Jaina

9. Macobá

10. Santa Rosa Xtampak 11. Sihó
$\mathrm{X}$

-

-

$\mathrm{X}$

$\mathrm{X}$

$\mathrm{X}$

$\mathrm{x}$

-

$\mathrm{X}$

$\mathrm{X}$

$\mathrm{X}$
Pollock, 1980

Benavides, 1991:49

Müller, 1960

Pollock, 1970; Nelson, 1973

Matheny et al., 1983; Benavides, 1997

Pollock, 1980; Williams, 1998

Von Euw, 1977

Piña, 1968

Andrews, 1997

Pollock, 1970; Andrews, 1997

Dunning y Andrews, 1994

La relación arriba expuesta debe considerarse como una hipótesis de trabajo sujeta a comprobación. Es evidente que no podemos comparar la extensión, complejidad y volumen construido de asentamientos como Edzná y Jaina, o Santa Rosa Xtampak versus Chunkán-Villa Madero. Obsérvese entonces como un ejercicio que intenta jerarquizar la distribución de los asentamientos del norte de Campeche. La sola presencia de estelas y/o juegos de pelota en uno u otro sitio puede también aplicarse de modo que elaboremos otro esquema explicativo.

También es importante comentar que otras ciudades mayas menores hoy son consideradas como tales por escasez de información, por destrucción de su patrimonio o simplemente por la cantidad, dimensiones y calidad de sus vestigios registrados. Ello no significa que no fuesen importantes, tanto como satélites de sus capitales regionales como por jugar un papel de enlace entre entidades políticas.

Uno de tales casos es Xcalumkín, en donde no hemos encontrado estelas, juego de pelota o grandes basamentos piramidales, pero sí cuenta con un buen número de textos jeroglíficos plasmados en columnas, jambas y dinteles. La discusión más reciente entre epigrafistas, historiadores de arte y arqueólogos esta relacionada con un glifo emblema que podría ser de Jaina o de Xcalumkín. Dicho elemento ha sido reportado en ambos asentamientos y su asignación permitiría hablar de una ciudad costera con su respectivo enclave tierra adentro o viceversa (cfr. Grube, 1994; García, 1998).

Por otra parte y dada la escasa información conocida de algunos de los sitios arriba listados o a ellos asociados, cabe aquí efectuar breves comentarios complementarios. Nos referimos especialmente a Calkiní, Campeche, Champotón, Chunkán-Villa Madero y Xcacab.

Calkiní es una importante cabecera municipal del norte de la entidad. Durante el virreinato también desempeñó un papel relevante a través de la evangelización, el control de la población indígena, la concentración de la producción agrícola y la exacción tributaria. Tampoco debemos olvidar que se halla justo a la mitad de lo que fue el Camino Real, que vinculaba a Mérida con Campeche. Precisamente por esa intensa actividad de casi cinco siglos los vestigios precolombinos de Calkiní han sido destruidos o modificados en gran medida. 
No obstante, en varias visitas a diversos puntos de Calkiní hemos constatado esa "pedacería" que indica la importancia de sus vestigios mayas. Algunos ejemplos son: 1) los montículos y cimientos de construcciones monumentales (con sillares Puuc) localizados en el sector noroeste de la población, sobre el trazo de la línea de alta tensión que se dirige a Nunkiní; 2) los numerosos sillares propios de la arquitectura Puuc que decoran la fachada del estadio principal, otros bloques labrados que forman muchas escarpas o banquetas, pisos de entrada a casas o que incluso se han usado en varias fachadas modernas; 3 ) varios sillares con relieves o partes de representaciones diversas (prehispánicos) que se emplearon en la construcción del convento de San Luis obispo; 4) muchos montículos mayas y chultunes asociados que aún se conservan en los patios o solares del asentamiento actual.

En un contexto mayor debemos recordar que Calkiní se localiza a unos $26 \mathrm{~km}$ al poniente de Uxmal, otrora poderosa capital precolombina con la cual seguramente tuvo diversos nexos a través de varios siglos. Calkiní también se halla en la ruta más corta (unos $70 \mathrm{~km}$ ) entre Uxmal y la línea costera. Un sitio "puente" entre ambas zonas arqueológicas es Xuch, cuyo registro arquitectónico incluye tres calzadas de piedra "que atraviesan la zona nuclear" (Williams-Beck, 1999: 23-25). Los recorridos realizados en los últimos años bajo la dirección de Williams-Beck y la recolección de cerámica en superficie han ido complementando los vacíos de información en esa parte norteña de Campeche. Al mismo tiempo se han identificado varios asentamientos mencionados en las fuentes coloniales tempranas.

El Campeche prehispánico corrió una suerte similar de destrucción y reutilización de sus inmuebles mayas. Además de la información consignada por Alberto Ruz (1969) debemos señalar la existencia de chultunes, sillares labrados a la usanza Puuc y tepalcates precolombinos en varios puntos de la ciudad. Sabemos, cuando menos, de tres depósitos pluviales registrados en los últimos años, dos en el barrio de San Román y otro en la colonia Bellavista. Los sillares podrían haberse traído de lugares distantes, pero los que forman parte de los muros del convento de San Francisco, los del barrio de Samulá y otros seguramente proceden de inmuebles que se hallaban cerca. Los tiestos, de clara factura maya, también se han hallado en las excavaciones del convento citado, en las de Puerta de Tierra, en las de la batería de San Lucas y en varias obras de infraestructura (agua potable, energía eléctrica, cableado telefónico, etcétera ) en diversos rumbos de la ciudad (Burgos, 1986; Suárez y Ojeda, 1996).

Los hallazgos más recientes de materiales prehispánicos en la ciudad de Campeche son aquellos producto de las excavaciones practicadas durante el año 2000 en el parque principal de la ciudad capital. Además de los vestigios virreinales de un inmueble religioso previo a la catedral, en estratos inferiores se encontraron vasijas y tiestos de tiempos precolombinos, la mayoría fechados para el periodo Clásico Tardío (600-900 d. C.). Casi a nivel freático también se registró parte de una plataforma prehispánica delimitada con sillares muy bien cortados, a la manera de las obras Puuc (Heber Ojeda, comunicación personal).

Existe otro factor propio de Campeche que comparten varios lugares prehispánicos: su asociación con el mar. La cercanía de los sitios nos ha llevado a pensar que la distribución del asentamiento fue más uniforme en la costa precisamente por el carácter lineal del litoral. Da la impresión de que hubo, simultáneamente, varios puntos que con-

BenaVides C. / EDZná Y la Región occidental del puUC

Estudios de Cultura Maya. Vol. XXIII, 2003

Instituto de Investigaciones Filológicas/

Centro de Estudios Mayas, UNAM

ISSN 0185-2574 
centraron bienes y servicios, y que la participación paralela en las labores comerciales quizá sólo llevó a una diferenciación en la medida en que lograran asociarse a un sitio grande del interior. Ello ayudaría a explicar el porqué no encontramos en la costa un sitio de dimensiones equiparables a Edzná o a Santa Rosa Xtampak.

La información hasta ahora reunida sobre los asentamientos prehispánicos costeros (cfr. Andrews y Vail, 1990) nos presenta un panorama de cierta uniformidad, con algunos núcleos más importantes a los que acompañan sitios menores pero sin que parezca existir la gran diferenciación de alguno en particular, como sucede tierra adentro.

Bajo nuestra perspectiva, esos puntos de mayor relevancia son Jaina, Campeche, el binomio Chunkán-Villa Madero y Champotón. En ellos observamos una mayor concentración de arquitectura monumental que en los sitios circundantes y, además, inscripciones jeroglíficas. La única excepción es Campeche, que suponemos carece de tales elementos debido a los fuertes cambios ocurridos a partir del siglo xvi. Otro caso ilustrativo (aunque algo alejado) de la gran pérdida de vestigios precolombinos es Mérida, cuya antigua importancia debería reflejarse en sus restos materiales.

Champotón también fue estudiado desde los sesenta por Ruz (1969: 34-36), especialmente el asentamiento costero, en buena medida perteneciente al periodo Posclásico y del cual incluso existen algunas referencias históricas. Pero hoy sabemos que los elementos prehispánicos de Champotón se localizan en ambas márgenes del río, es decir en los parajes denominados Champotón 1, Paraíso (hoy ocupado por la Secretaría de Marina) y en el conchero, reportados por Eaton y Ball (1978). Afortunadamente a los datos anteriores puede agregarse la existencia de numerosos montículos y, cuando menos, un grupo arquitectónico monumental en cuya estructura principal hubo bloques monolíticos que recuerdan la arquitectura petenera. Estos vestigios se localizan en el sector noreste de la mancha urbana actual y también se aprecian algunos montículos al oriente del inicio de la carretera que lleva a Escárcega. El asentamiento del periodo Clásico de Champotón se localiza a los $19^{\circ} 21^{\prime}$ latitud norte y $90^{\circ} 42^{\prime}$ de longitud oeste. Se encuentra a kilómetro y medio al sureste de la desembocadura del río. Su ubicación es similar a la de otros sitios precolombinos de la costa campechana como Villa Madero y Boxol, es decir a escasos kilómetros de la línea costera. Por lo visto, para el Posclásico hubo tendencia a incrementar el asentamiento sobre el litoral.

Algunos sillares precolombinos, incluso con inscripciones jeroglíficas, y que fueron reutilizados como material de construcción en los contrafuertes de la iglesia principal de Champotón (erigida al comenzar el siglo xvi) también revelan la cercanía de arquitectura monumental maya. Al efectuar el registro de dicho inmueble ubicamos tres de tales sillares (Figura 3). El primero (en el contrafuerte noreste) pudo ser un dintel o incluso una estela, pues su inscripción dobla en una de las esquinas y desconocemos si las partes amplias del monolito (tapadas por la mampostería superior e inferior que les rodea) contienen alguna representación. El texto combina numerales y el glifo del día ahau. Desconocemos la parte inicial de la inscripción y si está asociada a algún personaje o escena que pudiera existir en alguna de las caras anchas del monolito. En el sector visible podría leerse "... ahau; 15 ahau; 10, 9 ahau; 10, 13 ahau; 9 ahau". El uso exclusivo del día $a h a u$, el formato horizontal de los numerales y su empleo sin aparente referencia a otros signos causan confusión. Posiblemente sea una inscripción posclásica que no se apega a los cánones conocidos del periodo Clásico. 


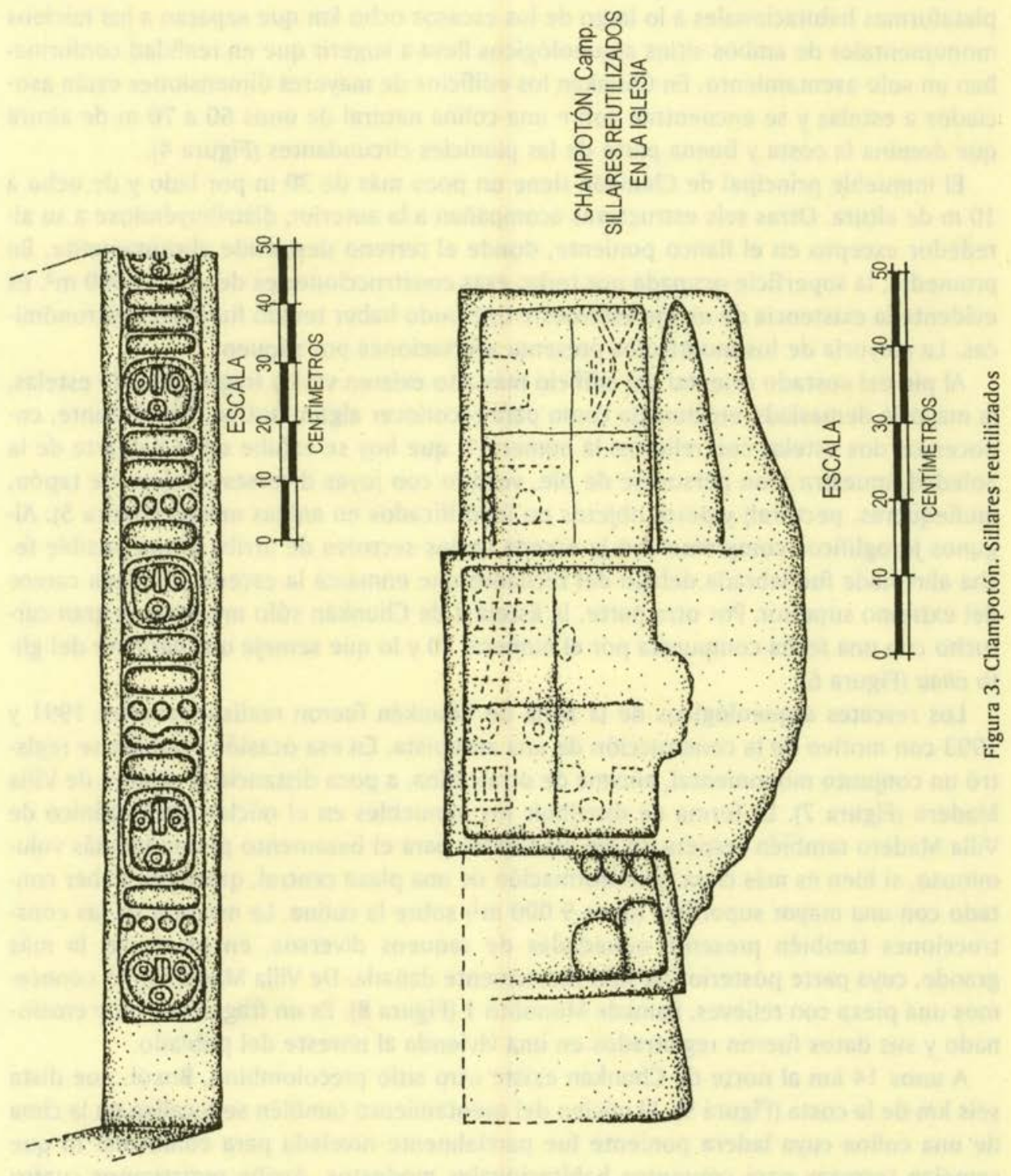

Estudios de Cultura Maya. Vol. XXIII, 2003 Instituto de Investigaciones Filológicas/

Centro de Estudios Mayas, UNAM 
El segundo sillar (en el contrafuerte sureste) es muy erosionado pero aún se aprecia que tuvo inscripciones en tres planos de la misma cara. Todos los jeroglíficos parecen estar agrupados de cuatro en cuatro, cada grupo enmarcado por una banda lisa. El tercer sillar es de menores dimensiones que los anteriores y su relieve no es entendible, tanto por estar erosionado como por encontrarse cubierto de argamasa.

Chunkán-Villa Madero. La presencia continua de montículos de varios tamaños y de plataformas habitacionales a lo largo de los escasos ocho km que separan a los núcleos monumentales de ambos sitios arqueológicos lleva a sugerir que en realidad conformaban un solo asentamiento. En Chunkán los edificios de mayores dimensiones están asociados a estelas y se encuentran sobre una colina natural de unos 60 a $70 \mathrm{~m}$ de altura que domina la costa y buena parte de las planicies circundantes (Figura 4).

El inmueble principal de Chunkán tiene un poco más de $30 \mathrm{~m}$ por lado y de ocho a $10 \mathrm{~m}$ de altura. Otras seis estructuras acompañan a la anterior, distribuyéndose a su alrededor excepto en el flanco poniente, donde el terreno desciende abruptamente. En promedio, la superficie ocupada por todas esas construcciones es de unos $3500 \mathrm{~m}^{2}$. Es evidente la existencia de un eje este-oeste que pudo haber tenido funciones astronómicas. La mayoría de los montículos presenta afectaciones por saqueo.

Al pie del costado oriental del edificio más alto existen varios fragmentos de estelas, la mayoría demasiado erosionada como para reconocer algún motivo. No obstante, conocemos dos estelas con relieves: la número 1 , que hoy se exhibe en el Baluarte de la Soledad, muestra a un personaje de pie, vestido con joyas diversas (orejera de tapón, muñequeras, pectoral) y porta objetos no identificados en ambas manos (Figura 5). Algunos jeroglíficos complementan la escena en los sectores de arriba y una posible fecha abreviada fue labrada debajo del recuadro que enmarca la escena. La pieza carece del extremo superior. Por otra parte, la Estela 2 de Chunkán sólo muestra un gran cartucho con una fecha compuesta por el numeral 10 y lo que semeja una variante del glifo ahau (Figura 6).

Los rescates arqueológicos de la zona de Chunkán fueron realizados entre 1991 y 1993 con motivo de la construcción de una autopista. En esa ocasión también se registró un conjunto monumental, encima de otra colina, a poca distancia al oriente de Villa Madero (Figura 7). La forma de distribuir los inmuebles en el núcleo prehispánico de Villa Madero también respeta un eje este-oeste para el basamento piramidal más voluminoso, si bien es más clara la conformación de una plaza central, quizá por haber contado con una mayor superficie (unos $9000 \mathrm{~m}^{2}$ ) sobre la colina. La mayoría de las construcciones también presenta oquedades de saqueos diversos, en particular la más grande, cuya parte posterior ha sido fuertemente dañada. De Villa Madero sólo conocemos una pieza con relieves, llamada Monolito 1 (Figura 8). Es un fragmento muy erosionado y sus datos fueron registrados en una vivienda al noreste del poblado.

A unos $14 \mathrm{~km}$ al norte de Chunkán existe otro sitio precolombino, Boxol, que dista seis $\mathrm{km}$ de la costa (Figura 9). El núcleo del asentamiento también se localiza en la cima de una colina cuya ladera poniente fue parcialmente nivelada para conformar lo que semejan terrazas para conjuntos habitacionales modestos. Arriba registramos cuatro inmuebles conformando una plaza. El edificio más grande mira al poniente. Las varias remociones y huecos de saqueo dejan entrever que hubo edificios recubiertos con sillares a la usanza Puuc. 


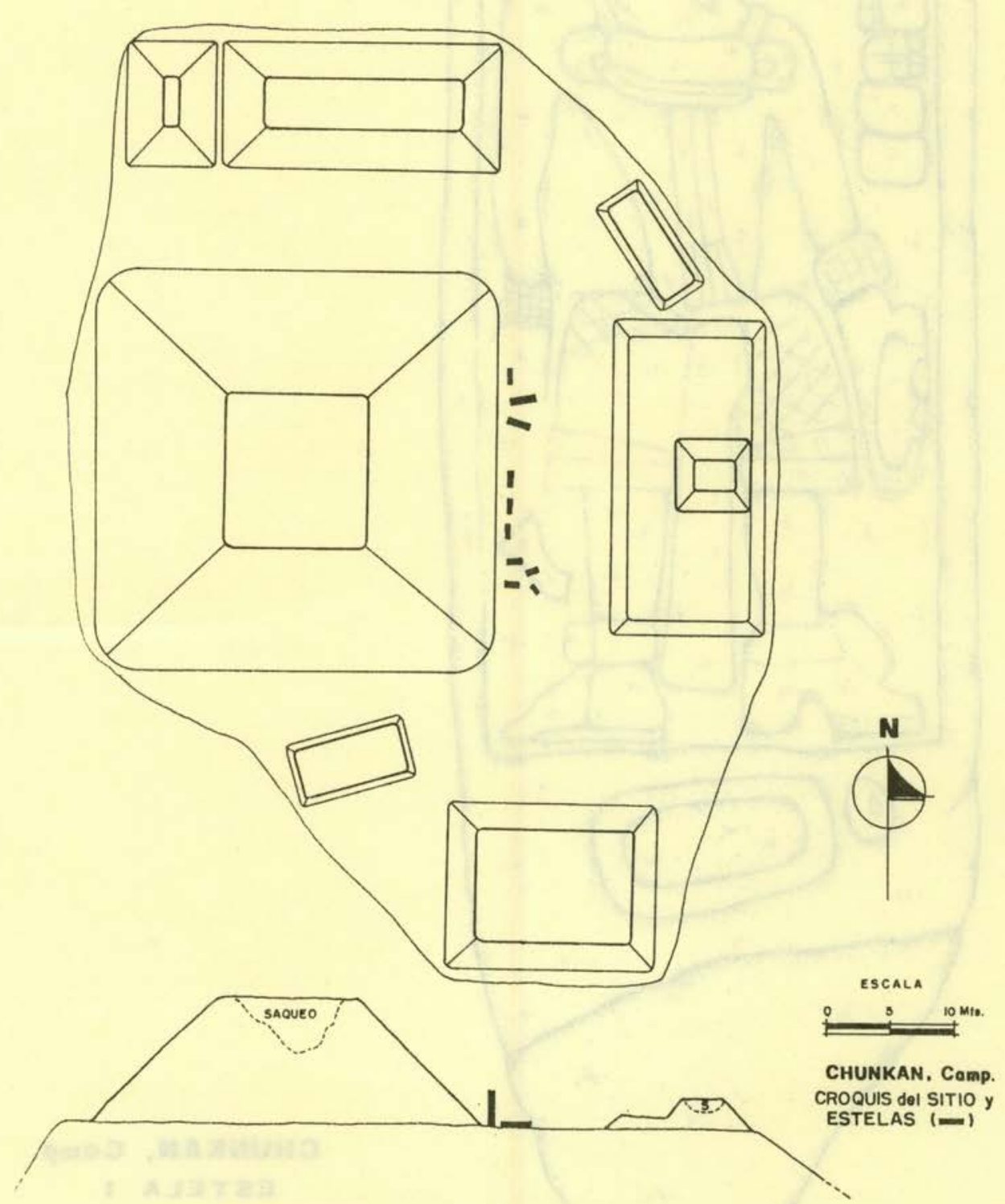

Figura 4. Chunkán, Campeche. Croquis del sitio

Estudios de Cultura Maya. Vol. XXIII, 2003

Instituto de Investigaciones Filológicas/

Centro de Estudios Mayas, UNAM

ISSN 0185-2574

http://www iifilologicas.unam.mx/estculmaya/ 

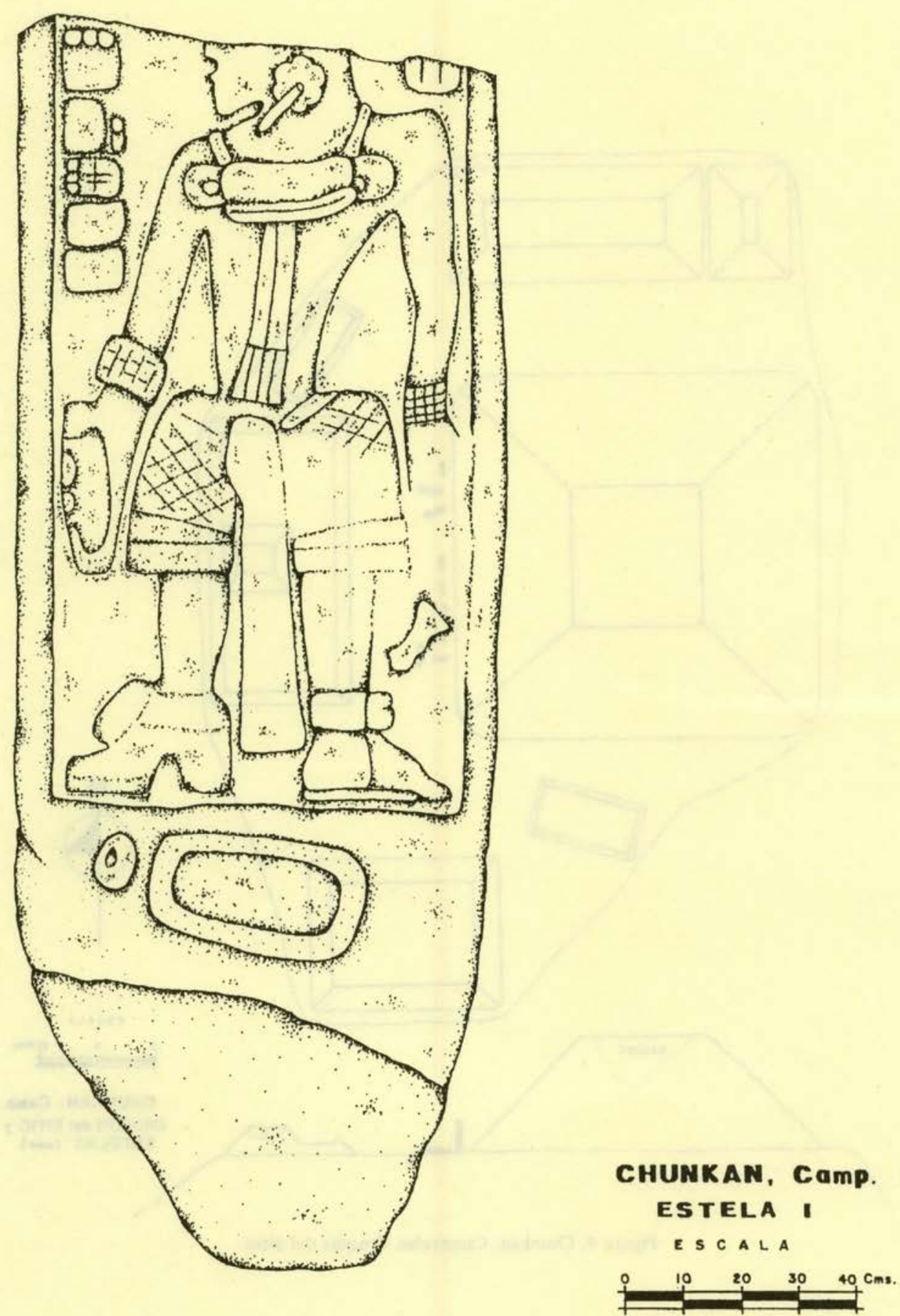

Figura 5. Chunkán, Campeche. Estela 1 


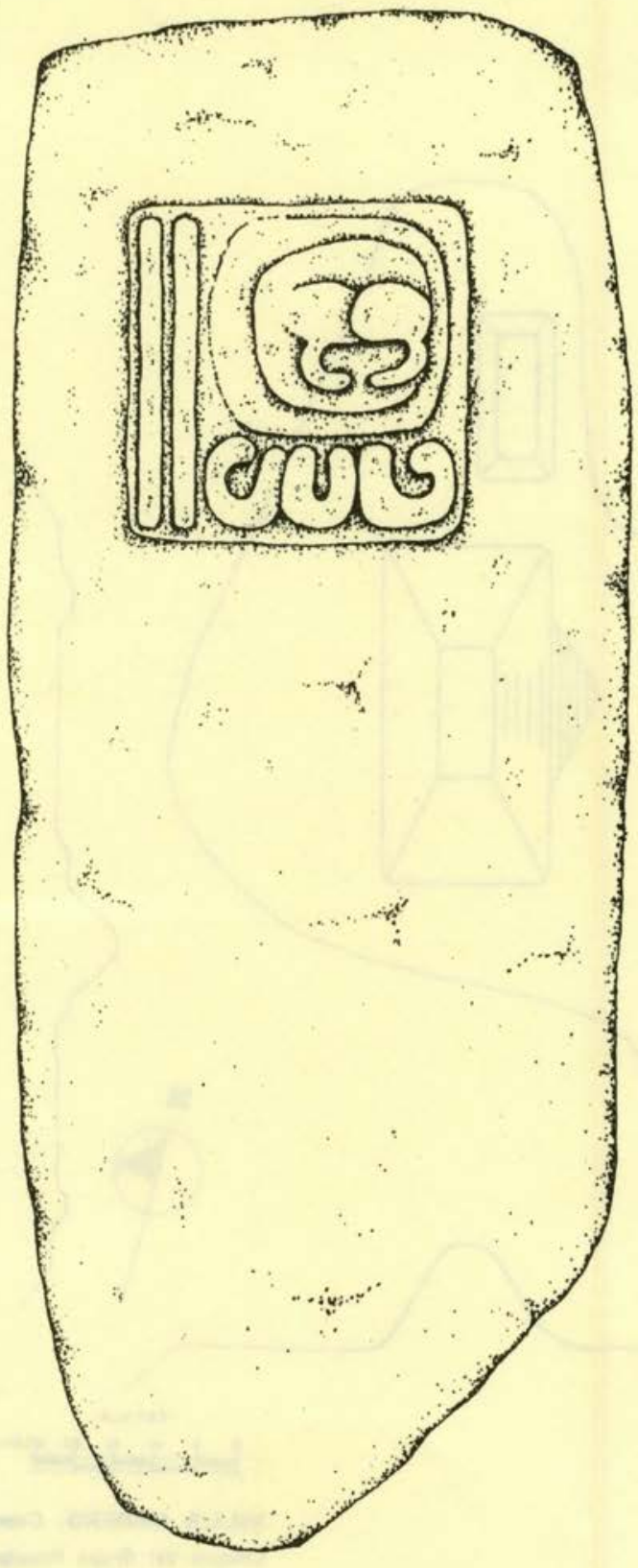

CHUNKAN, Camp.

ESTELA 2

E S C A L A

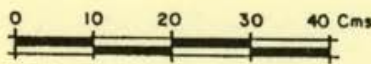

Figura 6. Chunkán, Campeche. Estela 2 


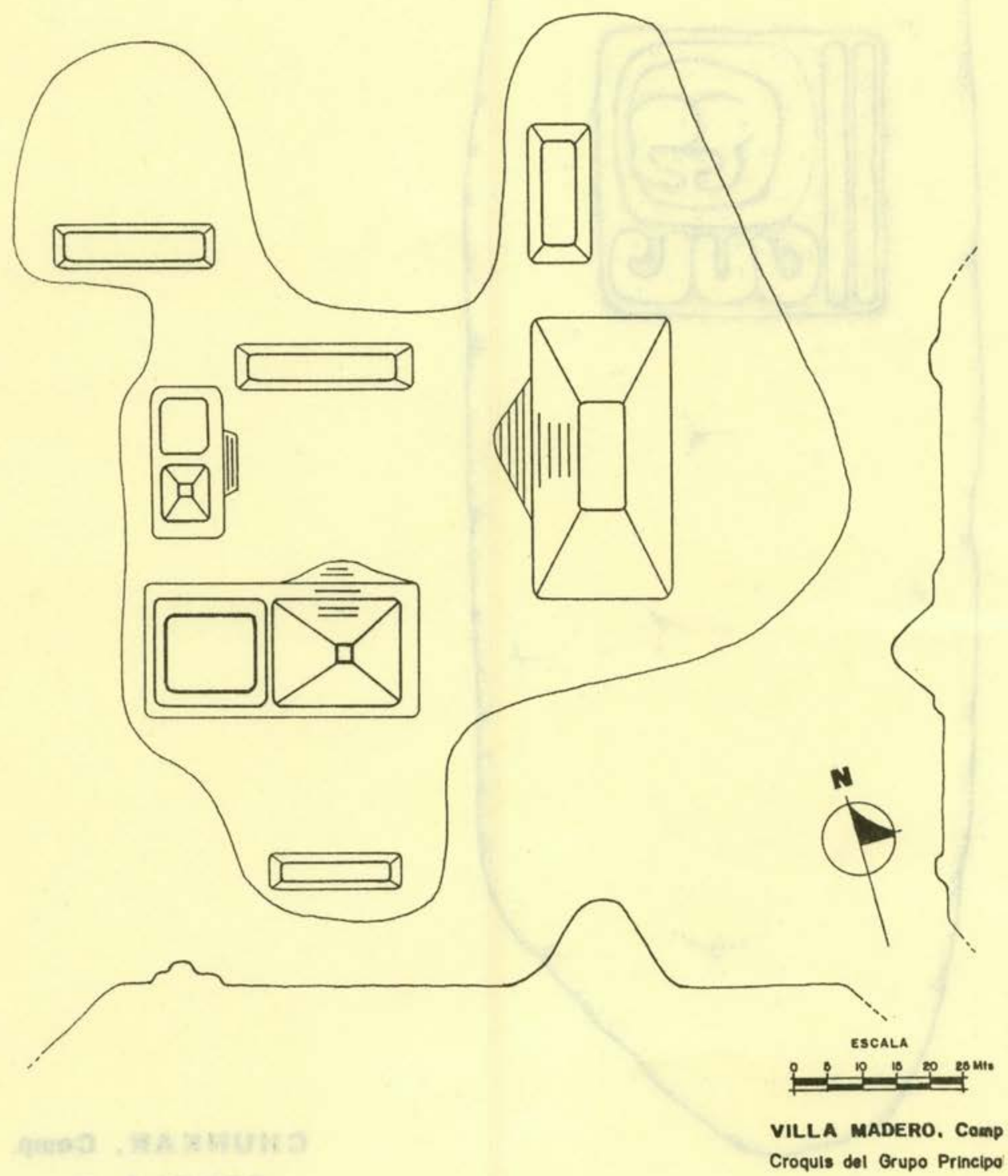

Figura 7. Villa Madero, Campeche. Croquis Instituto de Investigaciones Filológicas/

Centro de Estudios Mayas, UNAM ISSN 0185-2574

http://www iifilologicas unam mx/estculmaya/ 


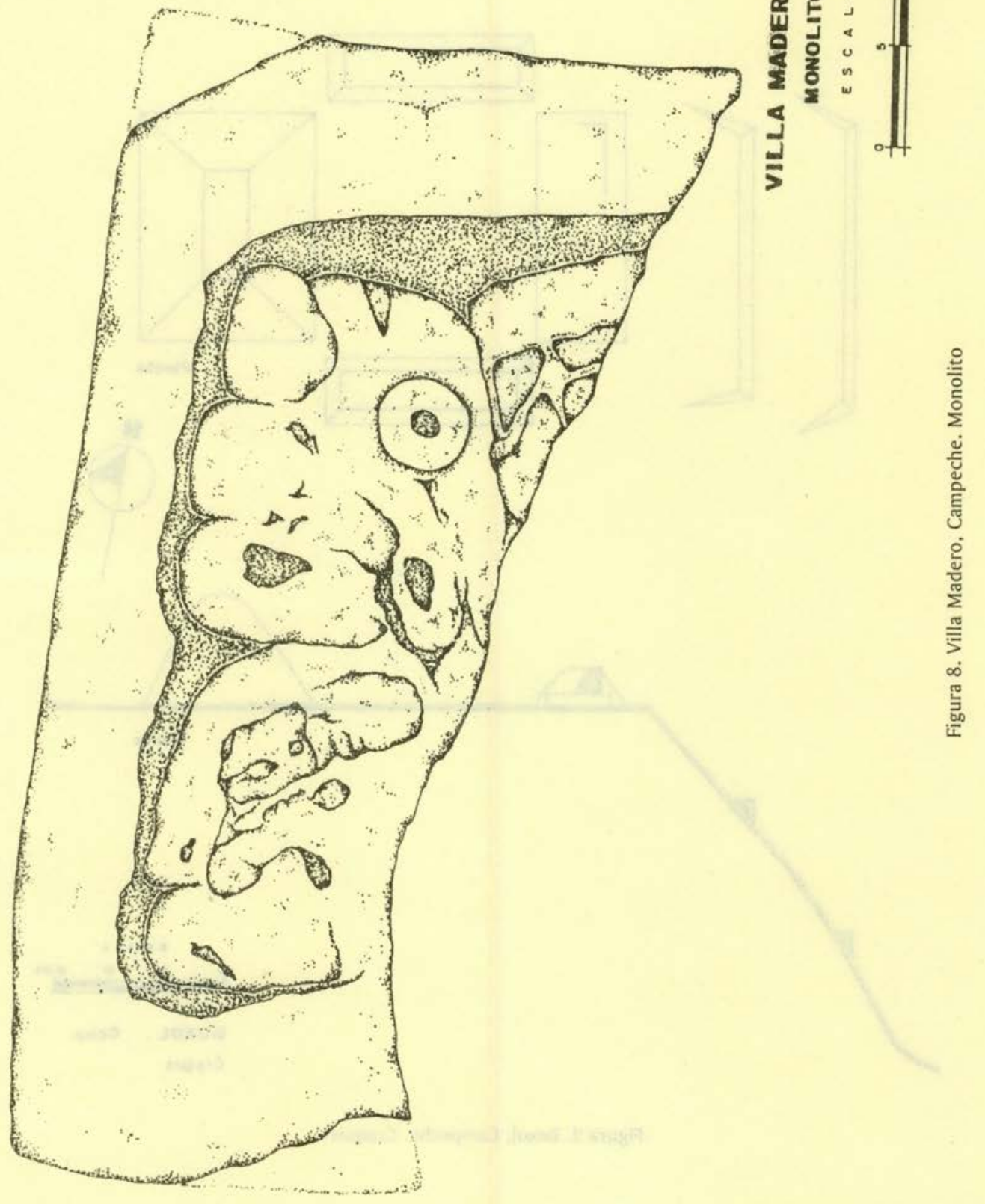

Estudios de Cultura Maya. Vol. XXIII, 2003

Instituto de Investigaciones Filológicas/

Centro de Estudios Mayas, UNAM

ISSN 0185-2574 

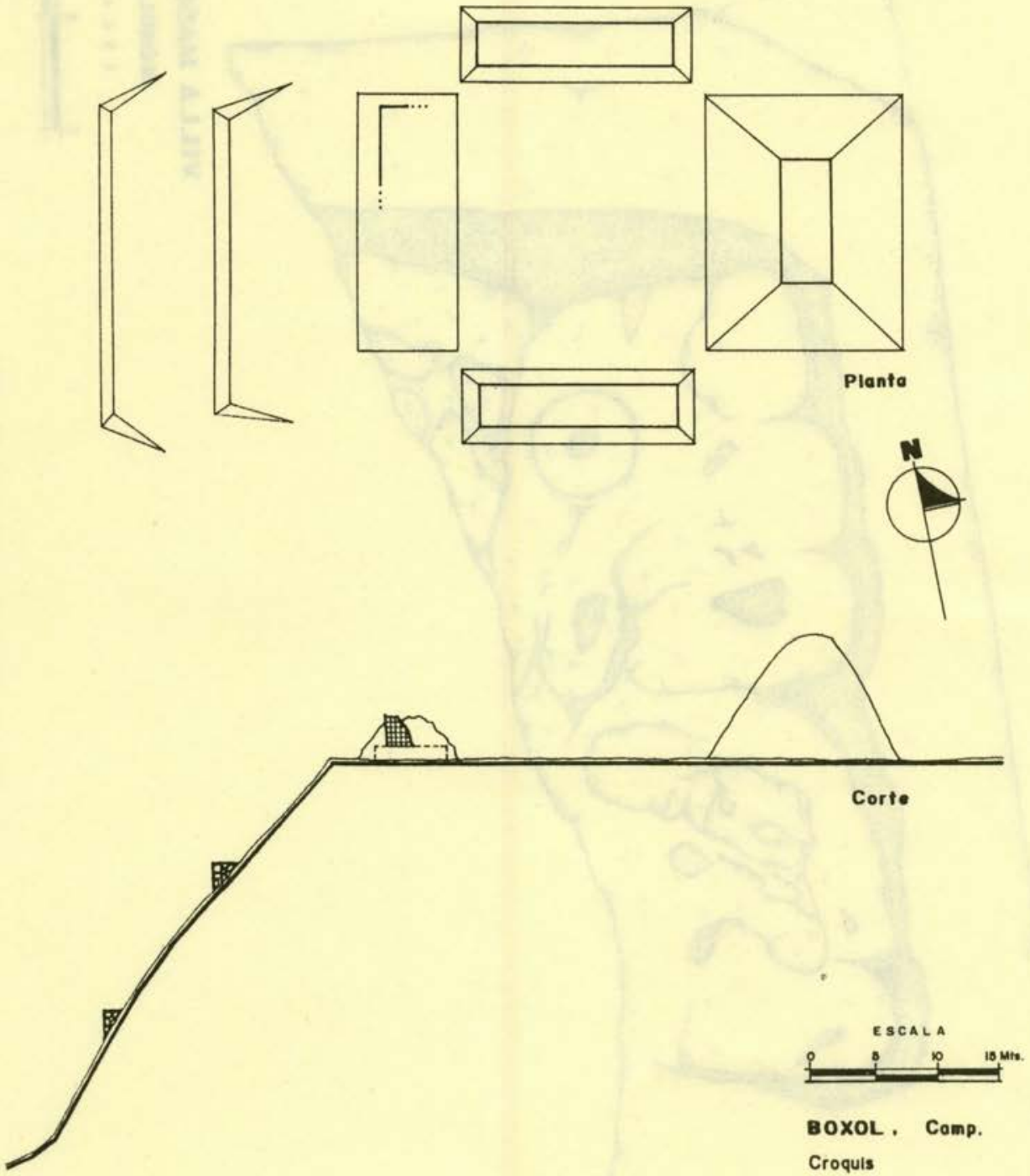

Figura 9. Boxol, Campeche. Croquis

Instituto de Investigaciones Filológicas/

Centro de Estudios Mayas, UNAM

ISSN 0185-2574

httn://www iifilologicas unam mx/estculmaya/ 
XCACAB, Comp.

"CROQuis PARCIAL."

( Bosodo en Williams 1908 ).
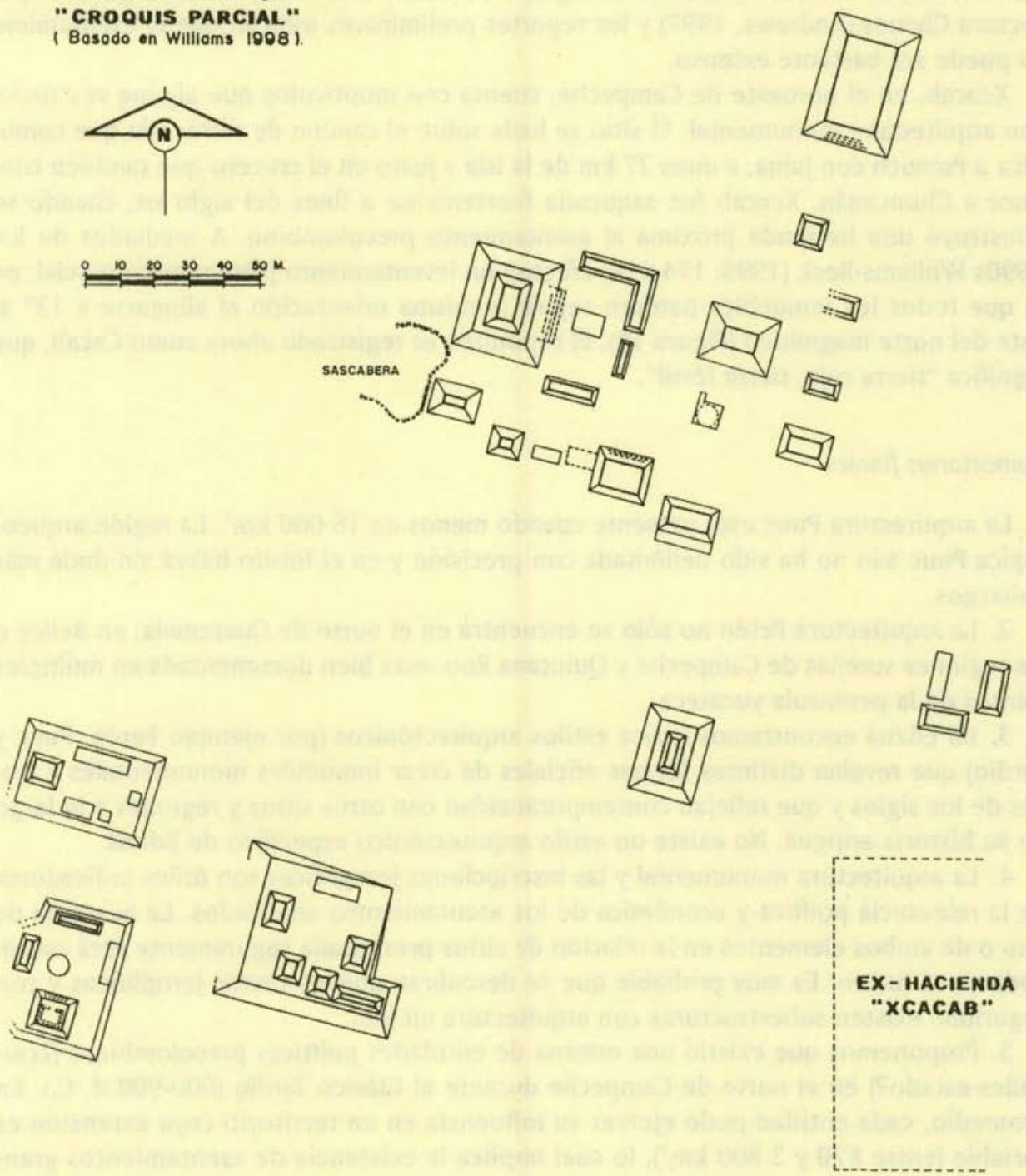

Figura 10. Xcacab, Campeche. Croquis

Estudios de Cultura Maya. Vol. XXIII, 2003

Instituto de Investigaciones Filológicas/

Centro de Estudios Mayas, UNAM

ISSN 0185-2574 
Macobá. Esta zona arqueológica se encuentra a unos $25 \mathrm{~km}$ al oriente de la comunidad de Iturbide (también conocida como Vicente Guerrero), en el municipio de Hopelchén. El sitio fue descubierto y brevemente descrito por el explorador Stephens, y visitado por pioneros de la arqueología maya como Teobert Maler y Harry Pollock. Durante varias décadas la zona permaneció oculta en la selva hasta que un grupo de investigadores la visitó de nuevo y efectuó el registro de cuatro inmuebles. Predomina la arquitectura Chenes (Andrews, 1997) y los reportes preliminares indican que el asentamiento puede ser bastante extenso.

Xcacab, en el noroeste de Campeche, cuenta con montículos que alguna vez tuvieron arquitectura monumental. El sitio se halla sobre el camino de terracería que comunica a Pomuch con Jaina, a unos $27 \mathrm{~km}$ de la isla y justo en el crucero que también conduce a Chuncanán. Xcacab fue saqueada fuertemente a fines del siglo XIX, cuando se construyó una hacienda próxima al asentamiento precolombino. A mediados de los 1990s Williams-Beck (1998: 174-178) efectuó un levantamiento planimétrico parcial, en el que todos los inmuebles parecen seguir la misma orientación al alinearse a $13^{\circ}$ al este del norte magnético (Figura 10). El topónimo es registrado ahora como Cacab, que significa "tierra roja, tierra fértil".

\section{Comentarios finales}

1. La arquitectura Puuc está presente cuando menos en $16000 \mathrm{~km}^{2}$. La región arqueológica Puuc aún no ha sido delimitada con precisión y en el futuro habrá sin duda más hallazgos.

2. La arquitectura Petén no sólo se encuentra en el norte de Guatemala, en Belice o las regiones sureñas de Campeche y Quintana Roo; está bien documentada en múltiples puntos de la península yucateca.

3. En Edzná encontramos varios estilos arquitectónicos (por ejemplo Petén, Puuc y Tardío) que revelan distintas formas oficiales de crear inmuebles monumentales a través de los siglos y que reflejan contemporaneidad con otros sitios y regiones a lo largo de su historia antigua. No existe un estilo arquitectónico específico de Edzná.

4. La arquitectura monumental y las inscripciones jeroglíficas son útiles indicadores de la relevancia política y económica de los asentamientos analizados. La ausencia de uno o de ambos elementos en la relación de sitios presentada seguramente será subsanada en el futuro. Es muy probable que se descubran nuevos textos jeroglíficos y con seguridad existen subestructuras con arquitectura en pie.

5. Proponemos que existió una oncena de entidades políticas precolombinas (Lciudades-estado?) en el norte de Campeche durante el Clásico Tardío (600-900 d. C.). En promedio, cada entidad pudo ejercer su influencia en un territorio cuya extensión es variable (entre 870 y $2800 \mathrm{~km}^{2}$ ), lo cual implica la existencia de asentamientos grandes de los que dependían varios satélites menores, así como las colindancias con sitios de poderío similar.

6. Ante el avance de las obras de infraestructura y de carácter agrícola, además de las operaciones ocasionales de saqueo y vandalismo, es prioritario proseguir el registro arquitectónico precolombino del centro y del norte de Campeche. Otra gran necesidad es una mayor protección y conservación de ese patrimonio. 


\section{BIBLIOGRAFÍA}

Andrews, Anthony P. y Gabriela Vail

1990 "Cronología de sitios prehispánicos costeros de la península yucateca", en Boletín de la ECAUDY, núms. 104-105, Mérida, Universidad Autónoma de Yucatán, pp. 37-66.

Andrews, George F.

1984 Edzna, Campeche, Mexico: Settlement Patterns and Monumental Architecture, Eugene, University of Oregon.

1985 "Chenes-Puuc Architecture: Chronology and Cultural Interaction", en Arquitectura y arqueología, México, CEMCA, pp. 10-39.

1986 Los estilos arquitectónicos del Puuc. Una nueva apreciación, México, INAH (Col. Científica, 150).

1995 Pyramids and Palaces. Monsters and Masks, vol. 1, Architecture of the Puuc Region, Lancaster, California, Labyrinthos.

1997 Pyramids and Palaces. Monsters and Masks, vol. 2, Architecture of the Chenes Region, Lancaster, California, Labyrinthos.

Ashmore, Wendy (ed.)

1981 Lowland Maya Settlement Patterns, Albuquerque, University of New Mexico Press.

Becquelin, Pierre, Dominique Michelet et al.

1994 "Proyecto arqueológico Xcalumkín en su trayectoria cronológica: segunda temporada (enero-marzo de 1993)", en Mexicon, núm. 5, vol. XVI, Möckmühl, pp. 93-99.

Benavides C., Antonio

1981 Los caminos de Cobá y sus implicaciones sociales, México, INAH.

1991 Geografia política de Campeche en el siglo XVI, México, INAH (Antologías, Serie Historia).

1994 "Edzná y el suroeste de la región del Puuc", en Prem (ed.), Hidden among the Hills. Acta Mesoamericana, núm. 7, Möckmühl, Verlag von Flemming, pp. 121-132.

1997 Edzná: una ciudad prehispánica de Campeche, México, INAH/University of Pittsburg.

Bueno Cano, Ricardo

1999 Entre un río de robles. Un acercamiento a la arqueología de la región Río Bec, México, INAH (Col. Científica, 411).

Burgos Villanueva, Rafael

1986 "Salvamento arqueológico en la batería de San Lucas, en la ciudad de Campeche", en Boletín de la ECAUDY, núm. 79, Mérida, Universidad Autónoma de Yucatán, pp. 11-18.

Dunning, Nicholas P.

1992 "Lords of the Hills: Ancient Maya Settlement in the Puuc Region, Yucatan, Mexico", en Monographs in World Archaeology, núm. 15, Madison, Wisconsin, Prehistory Press.

1994 "Puuc Ecology and Settlement Patterns", en Prem (ed.), Hidden among the Hills. Acta Mesoamericana, núm. 7, Möckmühl, Verlag von Flemming, pp. 1-4.

Dunning, Nicholas P. y George F. Andrews

1994 "Ancient Maya Architecture and Urbanism at Siho and the Western Puuc Region, Mexico", en Mexicon, núm. 3, vol. XVI, Möckmühl, pp. 53-61.

Eaton, Jack D. y Joseph W. Ball

1978 Studies in the Archaeology of Coastal Yucatan and Campeche, Mexico, Nueva Orleáns, Tulane University/Middle American Research Institute (Publicación 46).

BENAVIDES C. / EDZná Y La Región ocCidental del pUUC

Estudios de Cultura Maya. Vol. XXIII, 2003

Instituto de Investigaciones Fflológicas/

Centro de Estudios Mayas, UNAM

ISSN 0185-2574 
Fernández, Miguel Ángel

1946 "Los adoratorios de la Isla de Jaina", en Revista Mexicana de Estudios Antropológicos, núm. 8, México, Sociedad Mexicana de Antropología, pp. 243-260.

García Campillo, José Miguel

1998 "Datos epigráficos para la historia de Jaina durante el periodo Clásico", en Los Investigadores de la Cultura Maya, núm. 1, vol. 6, Campeche, Universidad Autónoma de Campeche, pp. 45-62.

Garza T., Silvia y Eduardo Kurjack

1980 Atlas arqueológico del estado de Yucatán, 2 vols., México, INAH.

Gendrop, Paul

1983 Los estilos Río Bec, Chenes y Puuc en la arquitectura maya, México, UNAM.

Graham, lan y Eric Von Euw

1992 Corpus of Maya Hieroglyphic Inscriptions, vol. 4, parte 3, Uxmal, Xcalumkin, Cambridge, Mass., Peabody Museum of Archaeology and Ethnology/Harvard University Press.

Grube, Nikolai

1994 "Hieroglyphic Sources for the History of Northwest Yucatan", en Prem (ed.), Hidden among the Hills. Acta Mesoamericana, núm. 7, Möckmühl, Verlag von Flemming, pp. 316-358.

Hansen, Richard

1998 "Continuity and Disjunction: the Preclassic Antecedents of Classic Maya Architecture", en Function and Meaning in Classic Maya Architecture, Washington, Dumbarton Oaks, pp. 49-122.

Maler, Teobert

1895 "Yukatekische forschungen", en Globus 68 (16), pp. 247-259; (18), pp. 277-292. Braunschweig.

1902 "Yukatekische forschungen", Globus 82 (13-14), pp. 197-230, Braunschweig.

1997 Península Yucatán, Berlin Gebr, Mann Verlag.

Matheny, Ray T.

1987 "An Early Maya Metropolis Uncovered, El Mirador", en National Geographic, núm. 172 , vol. 3, Washington, pp. 316-339.

Matheny, Ray T., D. Gurr et al.

1983 Investigations at Edzna, Campeche, Mexico, vol. 1, parte 1, The hydraulic system, Provo, Utah, Brigham Young University/New World Archaeological Foundation (Publicación 46).

Mathews, Peter

1991 "Classic Maya Emblem Glyphs", en P. Culbert (ed.), Classic Maya Political History, Cambridge, Cambridge University Press, pp. 19-29.

Mayer, Karl Herbert

1991 "The Archaeological Museum at Cayal, Campeche", en Mexicon, núm. 6, vol. XIII, Berlín, pp. 102-103.

Müller, Florencia

1960 Atlas arqueológico de la República Mexicana, vol. 2, México, INAH Campeche.

Nelson, Fred W.

1973 Archaeological Investigations at Dzibilnocac, Campeche, Mexico, Provo, Utah, Brigham Young University (Papers of the New World Archaeological Foundation, 33). 
Okoshi Harada, Tsubasa

1992 "Los Canules: análisis etnohistórico del Códice de Calkiní", México, UNAM, tesis de doctorado en antropología.

1997 "Organización político territorial de los Cupul y los Canul: un estudio de caso", ponencia inédita, presentada en la LXII Reunión Anual de la Society of American Archaeology, Nashville.

Piña Chan, Román

1968 Jaina. La casa en el agua, México, INAH.

Pollock, Harry E. D.

1970 "Architectural Notes on Some Chenes Ruins", en Bullard (ed.), Monographs and Papers in Maya Archaeology, Cambridge, Mass., Harvard University (Papers of the Peabody Museum of Archaeology \& Ethnology, 61), pp. 1-87.

1980 The Puuc. An Architectural Survey of the Hill Country of Yucatan and Northern Campeche, Mexico. Memoirs of the Peabody Museum of Archaeology \& Ethnology, Cambridge, Mass., Harvard University.

Roys, Ralph L.

1957 The Political Geography of the Yucatan Maya, Washington, Carnegie Institution of Washington (Publicación 613).

Ruppert, Karl y John Denison

1943 Archaeological Reconnaissance in Campeche, Quintana Roo and Peten, Washington, Carnegie Institution of Washington (Publicación 543).

Ruz Lhuillier, Alberto

1945 Campeche en la arqueología maya. Acta Anthropologica, vol. I, México, ENAH-Sociedad de Alumnos, pp. 2-3.

1969 La costa de Campeche en los tiempos prehispánicos, México, INAH (Serie Investigaciones, 18).

Sandoval P., J. M. y A. Morales

1982 "Una aproximación metodológica para el estudio de un sistema hidráulico prehispánico en Yohaltún, Valle de Edzná, Campeche”, en Boletín de la ECAUDY, núm. 53, Mérida, Universidad de Yucatán, pp. 13-27.

Stephens, John Lloyd

1963 Incidents of Travel in Yucatan, 2 vols., Nueva York, Dover Publications.

Suárez A., Vicente y Heber Ojeda M.

1996 Arqueología histórica en la ciudad de Campeche, Campeche, Universidad Autónoma de Campeche.

Valiente Cánovas, Santiago

1989 "El Palacio Ch'ich y el Palacio del Diablo", en Oxkintok, núm. 2, Madrid, Misión Arqueológica de España en México, pp. 30-41.

Von Euw, Eric

1977 Corpus of Maya Hieroglyphic Inscriptions, vol. 4, 1: Itzimté, Pixoy, Tzum, Cambridge, Peabody Museum.

Williams-Beck, Lorraine

1998 El dominio de los bataboob. El área Puuc occidental campechana, Campeche, Universidad Autónoma de Campeche.

BENAVIDES C. / EDZNÁ Y LA REGIÓN OCCIDENTAL DEL PUUC

Estudios de Cultura Maya. Vol. XXIII, 2003

Instituto de Investigaciones Filológicas/

Centro de Estudios Mayas, UNAM

ISSN 0185-2574 
1999 "La región al oriente de Calkiní: un acercamiento arqueológico de su historia lejana e inmediata", en Calkiní: una historia compartida, Campeche, Ayuntamiento de Calkiní, pp. 14-41.

Zapata P., Renée L.

1989 "Arqueología del noreste de Campeche", en Memorias del II Coloquio Internacional de Mayistas (1987), vol. 1, México, UNAM, IIFI, Centro de Estudios Mayas, pp. 427-448. 